\title{
Abdome agudo perfurativo em decorrência de uso de Crack: um relato de caso
}

\author{
Perfurative acute abdomen due to the use of Crack: a case report
}

\author{
Allana Maria Gomes Giordano ${ }^{1}$, Guilherme Bonassi Brechmacher ${ }^{1}$, Bruno Del Guercio von Sydow ${ }^{1}$, Diego \\ Ryuichi Silva Yosioka ${ }^{1}$, José Cesar Assef ${ }^{2}$
}

\section{Resumo}

O abdome agudo perfurativo é um diagnóstico sindrômico presente na rotina do pronto socorro. Nas perfurações do íleo terminal, as etiologias mais frequentes são as doenças inflamatórias intestinais (tuberculose intestinal e doença de Chron). Apresenta-se um caso onde a hipótese diagnóstica pré-operatória e a impressão intra-operatória era de perfuração por tuberculose intestinal. Contudo, frente ao resultado negativo no exame anatomopatológico, passou-se a discutir como etiologia o uso regular do Crack. A relação do uso da cocaina e seus derivados com complicações gastrointestinais é vista cada vez mais na prática médica, uma vez que o consumo da droga tem se difundido. Na literatura especula-se que a droga possa provocar vasoconstrição das artérias mesentéricas, isquemia tecidual focal, e em última instância, pode levar à perfuração.

Descritores: Abdome agudo, Perfuração intestinal, Cocaína crack, Tuberculose gastrointestinal

\begin{abstract}
The acute perforating abdomen is a syndromic diagnosis present in the emergency room routine. In perforations of the terminal ileum, the most frequent etiologies are inflammatory bowel diseases (intestinal tuberculosis and Chron disease). In the presented case, the preoperative clinical diagnostic hypothesis and intraoperative impression was
\end{abstract}

1. Acadêmico da Faculdade de Ciências Médicas da Santa Casa de São Paulo - $5^{\circ}$ Ano do Curso de Graduação em Medicina

2. Professor Adjunto da Faculdade de Ciências Médicas da Santa Casa de São Paulo - Departamento de Cirurgia. Diretor do Serviço de Emergência da Irmandade da Santa Casa de Misericórdia de São Paulo

Trabalho realizado: Hospital Central da Irmandade da Santa Casa de Misericórdia de São Paulo

Endereço para correspondência: Allana Maria Gomes Giordano. Rua Tabajaras 205 - Mooca - 03121-010 - São Paulo-SP - Brasil Declaração de conflito de interesse: Os autores relatam não haver conflito de interesse. perforation by intestinal tuberculosis. However, as opposed to the negative result in the anatomopathological exam, the regular use of Crack was pointed as an etiology. The relationship between the use of cocaine and its derivatives with gastrointestinal complications is increasingly found in medical practice, as drug use has spread. In the literature, it is speculated that the drug may cause vasoconstriction of the mesenteric arteries, focal tissue ischemia, and ultimately may lead to perforation.

Keywords: Abdomen, acute; Intestinal perforation; Crack cocaine; Tuberculosis, gastrointestinal

\section{Introdução}

O abdome agudo pode ser caracterizado por uma dor abdominal que leva o paciente a procurar assistência médica e necessita de terapêutica clínica ou cirúrgica na urgência. Na literatura, o abdome agudo é classificado em cinco tipos: inflamatório, obstrutivo, vascular, hemorrágico e perfurativo ${ }^{(1-3)}$.

Aventada a hipótese diagnóstica, pode ser necessária a solicitação de exames complementares, tanto laboratoriais, quanto de imagem, a fim de obter uma melhor elucidação da provável etiologia. Dentre os laboratoriais, podem-se destacar: hemograma, urina tipo I, beta-HCG, lipase, amilase, gasometria arterial. Em relação aos exames de imagem, a radiografia simples de tórax e abdome, a ultrassonografia e a tomografia computadorizada são os métodos utilizados, e a escolha de qual deles indicar depende da hipótese diagnóstica ${ }^{(1-3)}$.

Em relação ao abdome agudo perfurativo, seus principais sinais e sintomas são: dor abdominal súbita, fácies dolorosa, contratura involuntária do músculo reto-abdominal e Sinal de Jobert, forte indicativo de pneumoperitônio. Na radiografia simples de tórax e abdome, o pneumoperitônio faz o diagnóstico de abdome agudo perfurativo. Sabe-se que as principais etiologias são: úlceras gastroduodenais perfuradas, ingestão de corpo estranho e doenças inflamatórias intestinais ${ }^{(2)}$. 
Apesar de não ser uma causa comum, alguns autores vêm relacionando o consumo abusivo de cocaína e seus derivados, como o crack, a situações de abdome agudo perfurativo. Especula-se que o uso abusivo, principalmente agudo, dessas substâncias provoca vasoconstrição generalizada e intensa, levando a isquemia tecidual, uma vez que o crack/ cocaína alteram a recaptação de neurotransmissores como noradrenalina e dopamina, aumentando sua concentração sérica. Este processo pode desencadear uma série de alterações cardíacas, pulmonares, neurológicas, muscoloesqueléticas e gastrointestinais ${ }^{(4)}$.

No trato gastrointestinal (TGI), o aumento da concentração noradrenérgica pode provocar vasoconstrição das artérias mesentéricas, cuja consequência é isquemia tecidual focal, que em última instância, pode levar à perfuração da parede do TGI. Além disso, na vigência de uma doença de base, tal como úlcera péptica, o uso do entorpecente pode levar à perfuração da úlcera sem o processo isquêmico supracitado, evoluindo também para abdome agudo perfurativo ${ }^{(5)}$.

A presença de pneumoperitônio visto na radiografia simples é um sinal clássico de perfuração de víscera oca e a conduta deve ser cirúrgica. Vale ressaltar que mesmo que a radiografia não apresente pneumoperitônio, não se afasta a hipótese de abdome agudo perfurativo, e a presença de peritonite também é indicação de tratamento operatório ${ }^{(6)}$.

\section{Relato de Caso}

Paciente C. F. P. de 36 anos, sexo masculino, deu entrada no Pronto Socorro Central da Santa Casa de Misericórdia de São Paulo, com história de dor abdominal difusa associada a febre e enterorragia há 10 dias. Referiu ainda quadro súbito de piora da dor há 2 dias e negou fatores de melhora ou piora, bem como negou parada de eliminação de flatos ou fezes, vômitos ou outras queixas.

O paciente possuía como antecedentes pessoais o tratamento irregular para tuberculose no ano anterior, no qual fez uso do esquema COXIPE por 6 meses. Negava antecedentes cirúrgicos, e, relatava ser usuário de crack, e também ser morador de um albergue para pessoas sem moradia.

No exame físico o paciente encontrava-se em regular estado geral, descorado $1+/ 4+$, desidratado $2+/ 4+$, anictérico, acianótico, afebril e em posição antálgica. Ao analisar seu aparelho respiratório detectavam-se murmúrios vesiculares bilateralmente sem ruídos adventícios, sua frequência respiratória era de 20ipm, e, sua saturação de oxigênio em ar ambiente era de $96 \%$. Ao exame do aparelho cardiovascular obteve-se a ausculta de bulhas rítmicas normofonéticas em dois tempos sem sopro, a frequência cardíaca era de 100bpm e a pressão arterial sistêmica, de 130x90mmHg. O abdome do paciente apresentava contratura involuntária, timpanismo à percussão, os ruídos hidroaéreos estavam diminuídos na ausculta e detectava-se Sinal de Jobert. Ao exame dos membros, esses se apresentavam com boa perfusão periférica, tempo de enchimento capilar menor que 3 segundos e sem sinais de trombose venosa profunda.

Frente ao caso apresentado considerou-se a hipótese de abdome agudo perfurativo, e, como conduta escolhida, foram solicitados hemograma, exames de função renal, eletrólitos e radiografia de tórax e abdome. Além disso, foi também prescrita analgesia.

Os resultados dos exames estão listados abaixo:

\begin{tabular}{|c|c|c|}
\hline Exame & Resultado & Referência \\
\hline Hemoglobina & $9,9 \mathrm{~g} / \mathrm{dL}$ & 12,2 a $16,2 \mathrm{~g} / \mathrm{dL}$ \\
\hline Hematócrito & $29,4 \%$ & 37 a $47,9 \%$ \\
\hline Leucócitos & $\begin{array}{c}8,0 \mathrm{mil} / \mathrm{ul} \\
(10 \% \text { bastonetes })\end{array}$ & $4,6 \mathrm{a} 10,2 \mathrm{mil} / \mathrm{ul}$ \\
\hline Plaquetas & $180 \mathrm{mil} / \mathrm{ul}$ & 142 a $424 \mathrm{mil} / \mathrm{ul}$ \\
\hline Potássio & 4,4 & 3,5 a $5,1 \mathrm{mEq} / \mathrm{L}$ \\
\hline Sódio & 140 & 136 a $145 \mathrm{mEq} / \mathrm{L}$ \\
\hline Uréia & 45 & 10 a $45 \mathrm{mg} / \mathrm{dL}$ \\
\hline Creatinina & $1,1 \mathrm{mg} / \mathrm{dL}$ & 0,6 a $1,3 \mathrm{mg} / \mathrm{dL}$ \\
\hline
\end{tabular}
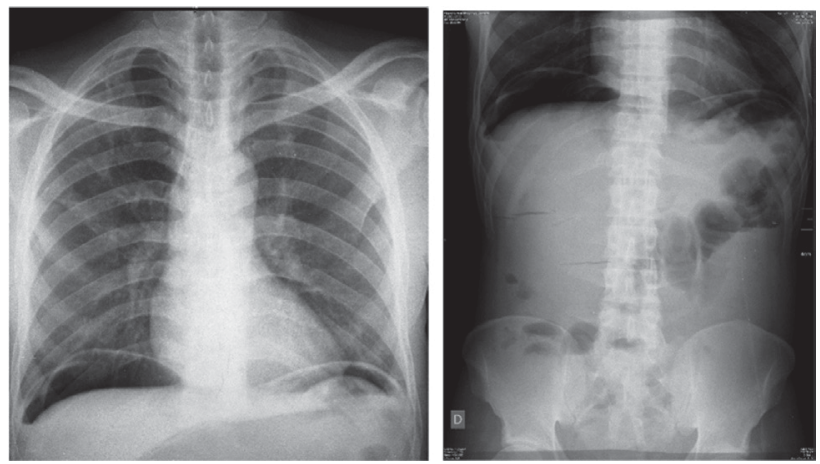

Nas radiografias é possível observar a presença de pneumoperitônio bilateral (à direita vê-se uma camada de ar entre a cúpula diafragmática e o fígado, e, à esquerda, entre a cúpula diafragmática e a câmara gástrica), além da visualização de pequena quantidade de líquido livre na cavidade abdominal. Devido a esses achados o paciente foi levado ao centro cirúrgico para realização de uma laparotomia exploradora.

No intra-operatório foi visualizado uma moderada quantidade de líquido entérico na cavidade. Não foram encontradas alterações no estômago ou duodeno. Contudo foram visualizado dois pontos de perfuração de aspecto inflamatório em íleo distal, a aproximadamente $40 \mathrm{~cm}$ da válvula ileocecal, associado a linfonodomegalia adjacente. 
Frente a estes achados, foi então realizada lavagem da cavidade com soro fisiológico; uma enterectomia segmentar a aproximadamente $30-40 \mathrm{~cm}$ da válvula íleo-cecal com confecção de estomia a Mikulicz, além de biópsias excisionais dos linfonodos de mesocólon adjacente, juntamente com a peça de enterectomia.

No primeiro pós-operatório o paciente se apresentava estável, em bom estado geral, estomia em bom aspecto, ferida operatória em bom aspecto com saída de secreção serosanguinolenta e recebia ciprofloxacino, metronidazol e ampicilina.

No oitavo pós-operatório paciente evoluiu com eventração e saída de secreção serosa pela ferida operatória - laboratoriais: PCR 3,8; leucócitos 5,8 mil sem desvio; hemoglobina 9,4.

No décimo pós-operatório paciente evoluiu com evisceração e foi então reabordado cirurgicamente. No intra-operatório foi visto que havia edema e distensão das alças do intestino delgado e também, uma pequena quantidade de líquido seroso livre na cavidade. A aponeurose foi então suturada com pontos separados em U com fio Prolene ${ }^{\circledR} 2-0$.

No décimo-nono pós-operatório paciente estava estável, aceitando bem a dieta via oral com estomia funcionante, e, a ferida operatória se apresentava em bom aspecto. O resultado do anatomopatológico descrevia o intestino delgado com distúrbio circulatório hemorrágico, serosite aguda e purulenta e formação de abscesso; linfonodos com hiperplasia linfoide reacional.

\section{Discussão}

Nas perfurações do íleo terminal, as etiologias mais frequentes são as doenças inflamatórias intestinais (tuberculose intestinal e doença de Chron). No caso em questão, a impressão intra-operatória era de perfuração por tuberculose intestinal.

Essa doença apresenta como principal sítio de acometimento a região ileocecal ( $64 \%$ dos casos), sendo o íleo terminal a região mais comumente afetada, por diversos fatores: estase, presença de tecido linfoide em abundância, alta taxa de reabsorção no local, e contato mais fácil do bacilo com a mucosa ${ }^{(7)}$.

O diagnóstico pode ser muito desafiador, principalmente por mimetizar outras doenças granulomatosas inflamatórias do TGI e provocar sintomas muito inespecíficos, podendo, muitas vezes, apresentar-se unicamente como uma dor abdominal. Além disso, faltam exames - radiológicos ou microbiológicos com boa sensibilidade e/ou especificidade para o seu diagnóstico ${ }^{(4)}$.

A tuberculose intestinal pode apresentar-se macroscopicamente sob 3 formas: ulcerativa, hipertrófica e úlcero-hipertrófica.
A forma ulcerativa representa $60 \%$ dos casos, e ocorre na forma de múltiplas úlceras superficiais tipicamente numa orientação transversal ou circunferencial, em relação ao eixo longo do lúmen do intestino. No caso da forma hipertrófica, que corresponde a $10 \%$ dos casos, podem ser observadas cicatrizes, fibrose e lesões pseudotumorais. Por último, a úlcero-hipertrófica (30\% dos casos), apresenta-se como uma massa inflamatória em torno da válvula ileocecal com paredes intestinais espessadas e ulce$\operatorname{radas}^{(8)}$.

O manejo dessa doença depende da apresentação e das complicações associadas, e na presença de perfuração do intestino ou sangramento maciço, a exploração cirúrgica emergencial, com tratamento direcionado, é o procedimento de escolha ${ }^{(9-11)}$.

Por ter relatado tratamento irregular para tuberculose no ano anterior, uma das hipóteses cogitadas para explicar a causa do abdome agudo perfurativo do paciente foi a tuberculose intestinal, iniciando-se o protocolo de tratamento cirúrgico.

Contudo, frente ao resultado negativo no exame anatomopatológico, passou-se a discutir como etiologia da perfuração o uso regular do crack. Corroborava para essa hipótese, o fato do paciente apresentar pneumoperitônio, comumente encontrado nas perfurações por abuso de entorpecentes derivados da cocaína ${ }^{(12)}$.

A cocaína é uma droga de abuso muito difundida na população mundial, comercializada ilegalmente sob duas formas mais comuns: o pó branco e o crack (forma de base livre). Aproximadamente 2,2\% da população brasileira consome derivados de cocaína, principalmente entre adolescentes e adultos do sexo masculino ${ }^{(13)}$.

A ação da cocaína ocorre no neurônio présináptico, impedindo a recaptação da norepinefrina, gerando acúmulo desse neurotransmissor. Uma vez que a vasculatura intestinal apresenta receptores alfa-adrenérgicos o acúmulo noradrenérgico, leva à vasoconstrição, que pode evoluir para isquemia e até perfurações intestinais. Devido a esse mecanismo, o aumento no consumo do crack vem refletindo em um aumento significativo nas lesões isquêmicas no TGI.

Outras complicações que também podem ser encontradas em decorrência do uso abusivo desses entorpecentes são: isquemia do miocárdio e infarto, cardiomiopatia, isquemia cerebral, pneumopericárdio, hemorragia cerebral, edema pulmonar, rabdomiólise e infarto renal ${ }^{(5,14)}$.

\section{Considerações Finais}

A relação do uso da cocaína e seus derivados com complicações gastrointestinais é vista cada vez mais na prática médica, uma vez que o consumo da droga 
tem se difundido. Em pacientes que chegam ao pronto socorro com um quadro de dor abdominal aguda e uma clínica compatível com sinais de perfuração (sinais difusos de peritonite, presença de Sinal de Jobert), independentemente de haver ou não pneumoperitônio visível na radiografia, deve-se cogitar a hipótese de um abdome agudo perfurativo. Atentando-se sempre ao fato de que uma anamnese detalhada pode informar se o paciente faz uso abusivo de crack-cocaína para, assim, se compor uma hipótese diagnóstica sem desconsiderar possíveis etiologias.

\section{Referências}

1. Assef JC, Perlingeiro JAG. Dor abdominal. In: Assef JC, Perlingeiro JAG, Parreira JG, Soldá SC, editores. Emergências cirúrgicas traumáticas e não traumáticas: condutas e algoritmos. São Paulo: Atheneu; 2015. p.179-84.

2. Soldá SC, Almeira RF. Abdome agudo perforativo. In: Assef JC, Perlingeiro JAG, Parreira JG, Soldá SC, editores. Emergências cirúrgicas traumáticas e não traumáticas: condutas e algoritmos. São Paulo: Atheneu; 2015. p.249-53.

3. Brunetti A, Scarpelini S. Abdômen agudo. Medicina (Ribeirão Preto). 2007; 40 (3):358-67.

4. Burke KA, Patel A, Jayaratnam A, Thiruppathy K, Snooks SJ. Diagnosing abdominal tuberculosis in the acute abdomen. Int J Surg. 2014; 12(5):494-9.
5. Muñiz AE, Evans T. Acute gastrointestinal manifestations associated with use of crack. Am J Emerg Med. 2001; 19(1):61-3.

6. Bellows CF, Raafat AM. The surgical abdomen associated with cocaine abuse. J Emerg Med. 2002; 23(4):383-6.

7. Debi U, Ravisankar V, Prasad KK, Sinha SK, Sharma AK. Abdominal tuberculosis of the gastrointestinal tract: revisited. World J Gastroenterol. 2014; 20(40):14831-40.

8. Marshall JB. Tuberculosis of the gastrointestinal tract and peritoneum. Am J Gastroenterol. 1993;88(7):989-99.

9. Horvath KD, Whelan RL. Intestinal tuberculosis: return of an old disease. Am J Gastroenterol. 1998; 93(5):692-6.

10. Kapoor VK. Abdominal tuberculosis. Postgrad Med J. 1998; 74(874):459-67.

11. Aston NO. Abdominal tuberculosis. World J Surg. 1997; 21(5):492-9.

12. Cheng CL, Svesko V. Acute pyloric perforation after prolonged crack smoking. Ann Emerg Med. 1994; 23(1):126-8.

13. Abdalla RR, Madruga CS, Ribeiro M, Pinsky I, Caetano R, Laranjeira R. Prevalence of cocaine use in Brazil: data from the II Brazilian national alcohol and drugs survey (BNADS). Addict Behav. 2014; 39(1):297-301.

14. Wattoo MA, Osundeko O. Cocaine-induced intestinal ischemia. West J Med. 1999; 170(1):47-9.

Trabalho recebido: $28 / 05 / 2017$

Trabalho aprovado: 05/03/2018 